\title{
Investigating students' views about the role of writing in physics lab classes
}

Jessica R. Hoehn and H. J. Lewandowski

Department of Physics, University of Colorado, Boulder, Colorado 80309, USA and

JILA, National Institute of Standards and Technology and University of Colorado, Boulder, Colorado 80309, USA

Writing is an important aspect of experimental physics. Physics laboratory classes typically engage students in scientific documentation and writing in the forms of lab notebooks, reports, or proposals. Instructors of these classes may have a variety of motivations for incorporating writing. We previously developed a framework for thinking about the role of writing in physics lab classes that lists and categorizes possible goals instructors may have for writing. Here, we use that framework as a research tool to investigate students' views about, and experiences with, writing in lab classes, and experimental physics more generally. We present results of an analysis of student responses to weekly reflection questions throughout one semester of an advanced lab class. The results suggest that students think about writing in a variety of ways, and that the context and framing of the course may impact student thinking about the purpose of writing. 


\section{INTRODUCTION}

Laboratory classes are a crucial part of undergraduate physics education. As such, physics education researchers are increasingly investigating various aspects of student learning within lab class environments. Physics lab classes typically include some amount of scientific documentation and writing, which often takes the form of lab notebooks, reports, or proposals. Given that writing plays an important role in the process of experimental physics, it makes sense to have students learn about and practice scientific writing in lab classes. Indeed, many within the PER community have learning goals for lab classes that center around writing and communication [1-5]. However, there is a dearth of specific research on why and how we implement writing in lab classes.

Many lab classes, especially at the advanced level, give students the opportunity to design and conduct their own experiments [6]. Writing often plays a big role in such classes. The Joint Task Force on Undergraduate Physics Programs suggests that lab classes with a student-designed multiweek project will prepare students for 21 st century careers by providing "authentic research and communication experiences" [2]. We are interested in exploring various aspects of student learning during these student-designed projects.

In prior work, we developed a framework for thinking about the role of writing in lab classes; it consists of fifteen possible goals instructors may have for incorporating writing as part of a student-designed multiweek final project, organized into five categories [7]. Here, we use the framework as a research tool to investigate students' views about, and experiences with, writing in physics lab classes. We present a preliminary analysis of students' reflection responses from one semester of an advanced lab class in order to address the following three research questions: (1) What are students' views about the role of writing in lab classes? (2) What do students report learning from writing? (3) How does the specific course context manifest in students' approaches to writing?

\section{FRAMEWORK}

The framework [7] is a result of a coding analysis of four interviews with lab instructors that was corroborated and supplemented by literature on writing in science. The specific goals identified in the framework are organized into five broader categories-Communication, Writing as professionalization (WAP), Writing to learn (WTL), Course logistics, and Social emotional. Each category represents a distinct approach to writing, yet they often overlap or co-exist. For the present study, we focus our analysis at the level of these categories and conduct a course-grained investigation of students' views about, and experiences with, writing. In this section, we describe each of the five categories as articulated in the framework. Then, in Section III C, we provide examples of how we coded student reflections using the categories.

Communication. In physics and physics education, it is common to think about and treat writing primarily as a mode of communication. This category emphasizes the general idea of communication skills and treats writing as packaging for already formulated ideas, focusing largely on the final product of writing, rather than the process. Aligned with the communication category would be a view that the purpose of writing is for the writer to share what they know or what they did. In teaching physics lab classes, we may incorporate various forms of writing in order to help students improve their communication skills. Indeed, the general idea of communication is commonly included as a goal of physics lab classes $[1,5]$.

WAP. The WAP category foregrounds the importance of writing as a professional activity. Through engaging in writing in a physics lab class, students may learn and adopt professional discourse norms, practice disciplinary forms of reasoning or argumentation, and come to understand the central role that written communication plays in the process of science. Many physics lab classes include learning goals related to professionalization and discipline-specific modes of communication $[1,8]$. While in some contexts there may be significant overlap between the communication and WAP categories, the discipline-specific nature distinguishes WAP as its own category. Through practicing professional norms of written communication, students can become more central members of the professional community of physicists [9].

WTL. The WTL approach [10] treats writing as a tool to facilitate thinking and learning, foregrounding the process of writing rather than the final product. While the communication category treats writing as a package for already formulated ideas, the WTL category focuses on the creation, refinement, and articulation of those ideas. A WTL approach frames writing for students as a messy and iterative process that can be used to construct understanding, synthesize and clarify ideas, figure out solutions to problems, construct and refine arguments, and reflect on one's own views and experiences $[11,12]$. As such, the act of writing can facilitate learning both content and practices of physics through "frequent practice, effective feedback, and continual revision" [13].

Course logistics. The practical reality of physics lab classes is that writing assignments can play a crucial role in the structure of the class, allowing students to successfully complete experiments and instructors to successfully guide and evaluate the students' work. In the framework, the course logistics category contains two specific goals that instructors may have for writing: facilitating the project, and grading. A given piece of writing may be necessary to help the students make progress on their experiments, especially in the context of student-designed multiweek projects, by requiring them to plan ahead or by ensuring continuity from one lab session to the next. Or, the writing may serve as a way for instructors to evaluate students' progress and assign a grade. The course logistics category encompasses these practical and structural aspects of incorporating writing in lab classes.

Social emotional. As with any physics class, our goals for lab classes may include things like supporting student agency and identity, and facilitating positive affective experiences [1, 
14, 15]. Writing can be a vehicle through which to address these goals. The social emotional category refers to the role that writing can play in supporting students' experiences in the social environment of the lab class. This category does not appear in the student data we present in this paper, so we do not include it in the analysis below.

\section{METHODS}

As part of a broader research project, we partner with advanced lab instructors at multiple institutions across the US, and collect various forms of data. In this paper, we present preliminary analysis of one stream of data (weekly student reflections) for one semester of an advanced lab class.

\section{A. Course context}

The data we present in this paper come from an advanced physics lab course at a large, private, predominantly white, $\mathrm{PhD}$ granting research university in the western United States. The course typically enrolls 20 junior physics majors, split into two sections. In a 15 -week semester, it covers acoustics, micro fabrication, optics, and vacuum systems, and culminates with a 3 -week student-designed final project. The overall goal of the course is to prepare students to conduct research for their senior theses (though many students have already started research by the time they take the class). In our research, we focus on the final project portion of this class.

Writing plays a big role in the final projects. Though the students do not actually conduct their experiments until the final three weeks, they engage in a proposal process that begins in week 4 (W4) of the semester. Every student selects a topic of interest and writes a "white paper" to propose their own experiment. They engage in peer review of the white papers (every student reads a white paper from a student in the other section of the class), including a class-wide panel discussion. Then, the instructors select half of the proposed projects to receive "funding" (i.e., they get to go forward with the experiment). Funded and non-funded students team up in pairs to carry forward the funded projects. Each team first gives an oral presentation of the proposed project, and then submits a written proposal. The proposals are also peer reviewed, and the students have a chance to address reviewer feedback before submitting their final proposal and beginning to carry out the project. The proposal is intended to expand on the white paper and ensure that the students are prepared to conduct the experiment. In addition to the white paper and proposal, which comprises the bulk of the writing in the class, students are expected to keep lab notebooks throughout the semester.

While the overall goals for writing in this course address multiple categories in the framework, the implementation and framing of writing for the final project is particularly aligned with a WAP approach. The white paper and proposal process is intended to teach students about realistic practices within experimental physics, as well as to have the students learn and practice professional discourse norms. The use of the term "white paper" and the fact that some student proposals get "funded" are indications of this focus on professionalization.

The instructors directly convey this emphasis on WAP to the students. A final project explanation document included in the course materials informs students that the final project is intended, in part, "to help you learn how to identify, design, execute, and sell your ideas within a scientific community." In another course document that specifically outlines the white paper and proposal process, the instructors explain that a white paper is a "pre-proposal" required by some funding agencies. They tell the students that "The purpose of these activities is to give you practical experience in presenting a scientific plan in a way that is accurate, clear, and convincing. It will also give you insight into how the scientific funding process works." The students are also encouraged to consider the importance, relevance, and impact of their proposed experiment with respect to the broader scientific community.

These course materials demonstrate that the goals for, and framing of, writing in the class are aligned with a WAP approach. The white paper and proposal process is intended to teach students about a mode of professional writing, give students the opportunity to practice disciplinary norms of argumentation and communication, engage students in processes that mirror those in the professional scientific community, and teach students about the nature of experimental physics.

\section{B. Data collection}

Throughout the semester, the students completed online weekly reflection questions (receiving course credit for completion). There were two questions each week, and students were encouraged to complete them in the last few minutes of class time. The prompts varied depending on what the students were working on each week, and there were seven questions that asked specifically about writing:

- W1: What role do you anticipate writing will play in this class?

- W1: How might writing be helpful for you in conducting the labs, completing the final project, and learning about experimental physics?

- W7: What did you learn from the process of writing and reviewing white papers?

- W7: In what ways did the white paper review process help you think about your final project?

- W11: What did you learn from the process of writing and refining your final project proposal?

- W11: In what ways did the proposal review process help you think about your final project?

- W15: Why do you think writing is included in this class? The questions in the first and last weeks of the semester ask about students' views of writing. In week 1 (W1), we ask them to anticipate the role of writing. Responses to these questions will indicate students' expectations or views about 
what role writing should or will play in learning about experimental physics. In week 15 (W15), we ask the students to reflect back on the course overall and think about why the instructors and course designers may have included writing in the course. Responses to this question will indicate students' overall impressions of, or views about, the role of writing in the class [16]. We refer to these three general questions that probe students' views of writing as the "views questions."

The other four questions (weeks 7 and 11), are more specific in that they ask students to reflect on their experiences with the writing assignments. Responses to these questions will indicate the ways in which students engaged with the writing and what role the students saw the writing play in their overall learning. We refer to these four questions as the "experiences questions" and include them in the analysis in aggregate since the four questions together probe the majority of the writing associated with the final project in this class.

In this paper, we present results from a preliminary analysis of the students' reflection responses during the Winter 2020 semester. There were 21 students enrolled in the course; however, beginning in week 11 the response rate to the reflection surveys dropped. This drop coincides with the disruption to the class due to the COVID-19 pandemic. Because all of the white paper and proposal writing was completed prior to this disruption, we do not think the data are significantly impacted beyond the lower response rate in later weeks.

\section{Data analysis}

The original framework describes goals that instructors may have for incorporating writing in lab classes. We find that the elements of the framework are also applicable to student perspectives, but the codes may have slightly different meaning when applied to student responses. We began with a codebook derived from the original framework and engaged in an iterative process of refining and operationalizing it as we applied it to the student data for the present study. We looked for each of the five category codes described above in Section II, but the social emotional category did not appear in the data, so we do not include it in the analysis. A summary of the resulting codebook is shown in Table I.

There were 122 total responses to the seven questions, and most responses consisted of one to two sentences. We applied the four category codes (Table I) to the data; a code could not be applied more than once in a given response, but there were many instances of multiple different codes applied to a single response, and some instances of responses that did not receive any codes. There were a total of 108 codes applied. The research team conducted confirmatory inter-rater reliability on a random subset of the data and ultimately reached $100 \%$ consensus. With this mutual understanding of the codebook, the first author then coded the entirety of the dataset. Upon coding the data, we looked at counts of codes by question and in aggregate. We keep the results of the views and experiences questions separate from one another. The results for the views questions help us address our first research question about students' views of writing, and the results for the experiences questions help us address our second research question about the role that students see writing play in their learning.

\section{RESULTS}

The results of the coding analysis are displayed in Table II. The number of codes are presented as a percentage of total responses for a given question, or group of questions. Because a given response could be coded with multiple different codes (or no codes), the percentages in each column do not sum to $100 \%$. The responses that were not coded contained no information about students' approaches to, or experiences with, writing (e.g., listing writing assignments in the course syllabus with no elaboration of their personal opinion, interpretation, expectation, or experience).

There are three main results we will focus on in this paper. First, the total results for the views questions are roughly evenly distributed across the four categories. That is, the students did not cluster in one category, but rather viewed writing in a variety of ways. Second, the results for W15 look different from those in W1. Responses to the W1 questions asking students to anticipate the role that writing would play in the class and for their learning were distributed evenly across the four categories. The W15 question asked students to reflect back on the class overall and consider the purpose of writing in the class; the majority (77\%) of responses were coded as WAP, with $8 \%$ for each of the other categories. Finally, while the communication category made up $24 \%$ of the views responses (primarily from the W1 questions), it essentially does not appear in the experiences responses. That is, when students talked about what they learned from engaging in the white paper and proposal writing process, they only mentioned communication $3 \%$ of the time; the rest of the experiences responses were roughly evenly distributed across the WAP, WTL, and course logistics categories.

\section{DISCUSSION AND CONCLUSIONS}

We see a strong connection between the framing of writing within the course and the results of the coding analysis. As illustrated in Sec. III A, the messaging to students about the purpose of writing in the class emphasizes WAP. Students are required to learn about and engage in a professional mode of writing, and are told that this will not only help them complete their projects, but also learn about realistic scientific practice. Correspondingly, in the final reflection, students talk primarily about WAP-related ideas when discussing the purpose of writing in the course. The fact that there was only one response (out of 13) coded as course logistics for this question is notable, since things like grading fall under the course logistics category. We might expect that, at the end of the semester, grading and other logistical matters would be 
TABLE I. Summary of the four category codes that appeared in the data-Communication, WAP, WTL, and Course logistics.

\begin{tabular}{lll}
\hline \hline Category & Description & Example student response \\
\hline Comm. & $\begin{array}{l}\text { Purpose of writing is to demonstrate what you know or what } \\
\text { you did; developing general communication skills }\end{array}$ & $\begin{array}{l}\text { Writing will help me present my ideas and findings in a way } \\
\text { that others can understand }\end{array}$ \\
WAP & $\begin{array}{l}\text { Discipline-specific; learning professional norms/practices; } \\
\text { writing as something that scientists do }\end{array}$ & $\begin{array}{l}\text { Experimental physicists do a lot of writing in their work. } \\
\text { Projects need to be well documented for various purposes } \\
\text { and project proposals are another key part to their work. }\end{array}$ \\
WTL & $\begin{array}{l}\text { Writing as a tool for thinking and learning; focuses on the } \\
\text { process of writing }\end{array}$ & $\begin{array}{l}\text { Writing helps me organize my thoughts so I understand the } \\
\text { principles better. Anyone can jump through hoops, but writ- } \\
\text { ing helps you understand why you're actually doing the labs. } \\
\text { Course log. }\end{array}$ \\
& $\begin{array}{l}\text { Writing as something that helps the project or class move } \\
\text { forward }\end{array}$ & $\begin{array}{l}\text { Keeping accurate notes in a journal so that I can pick up in } \\
\text { the next class where I left off. }\end{array}$ \\
\hline \hline
\end{tabular}

TABLE II. Percentage of responses coded in each category for 3 views questions (by week, and in aggregate) and 4 experiences questions (in aggregate). Columns do not sum to $100 \%$ because a given response could be coded with zero, one, or multiple categories.

\begin{tabular}{lcccc}
\hline \hline & \multicolumn{3}{c}{ Views } & \multicolumn{2}{c}{$\begin{array}{c}\text { Experiences } \\
\text { Total }(\mathbf{N = 6 7})\end{array}$} \\
& W1 (N=42) & $\mathbf{W 1 5}(\mathbf{N = 1 3})$ & Total $(\mathbf{N = 5 5})$ & $3 \%$ \\
Comm. & $29 \%$ & $8 \%$ & $24 \%$ & $3 \%$ \\
WAP & $17 \%$ & $77 \%$ & $31 \%$ & $36 \%$ \\
WTL & $12 \%$ & $8 \%$ & $11 \%$ & $33 \%$ \\
Course log. & $19 \%$ & $8 \%$ & $16 \%$ & $22 \%$ \\
\hline \hline
\end{tabular}

on the forefront of students' minds. Instead, the course emphasis on WAP manifests in students' reflections. As such, we see this course as a successful example of teaching about professional writing and using writing to help students learn about what it means to do experimental physics.

However, even with an emphasis on WAP in the course, the students still exhibited a broad range of thinking about writing overall, as evidenced by the distribution across all four categories for the views questions. Thus, instructors need not be restricted to one approach to writing in their classes. The results of this study suggest that students are capable of thinking about, and engaging with, writing in a variety of ways, but also that if instructors have a particular goal for the way they want students to see and engage with writing (e.g., WAP), they can structure their course accordingly.

The idea of writing as communication is perhaps the most salient, intuitive, and common approach within the physics community (compared to WAP or WTL). As such, we might expect students to gravitate towards this approach to writing. When asked generally about their views in W1 and W15, students talked about communication-related ideas $(24 \%$ of responses), but this category was not present when students wrote about their experiences with writing. In describing the actual process of writing as it unfolded (W7 and W11) and what they gained from it, WAP, WTL, and course logistics were most salient. Further, within the views questions, there is a decrease in communication codes from W1 (29\%) to W15 (8\%). In a lab class that incorporates a fair amount of writing, we might expect some students to come in with expectations that the sole purpose of writing is to communicate ideas, but then to realize that there is a lot more to it - that writing can help facilitate thinking and learning, and that writing is a professional activity with specific associated norms and practices. The results of this analysis are aligned with that interpretation. An alternative explanation, however, is that the differences in percentage of communication codes are driven by the phrasing of the questions we asked students. The experiences questions are phrased in a way that might lead students to focus on the process of writing rather than general communication aspects. However, the second W1 question is also leading in that way, and $19 \%$ of responses to that question were coded as communication. Thus, we believe the difference we see in communication responses is, at least in part, indication of a difference between students' general views and their in the moment experiences with writing.

Through this preliminary analysis, we have demonstrated that the framework, which originated from the instructor perspective, is also applicable to student thinking and writing. Additionally, this paper is an example of how the framework may be used as a research tool.

\section{FUTURE WORK}

The preliminary analysis presented in this paper provides a foundation for future work. We will expand on this initial study of students' views of, and experiences with, writing in three ways: 1) triangulate the reflection survey data with interview data in which students elaborate on their thinking around, and experiences with, writing, 2) conduct a finergrained analysis on this same dataset that investigates the fifteen specific goals from the framework [7], and 3) compare the results from this class to other classes at other institutions.

\section{ACKNOWLEDGMENTS}

The authors would like to thank the student and instructor participants in this project. This work is supported by NSF Grants No. DUE-1726045 and PHY-1734006. 
[1] J. Kozminski, H. J. Lewandowski, N. Beverly, S. Lindaas, D. Deardorff, A. Reagan, R. Dietz, R. Tagg, M. Eblen-ÂZayas, J. Williams, R. Hobbs, and B. Zwickl, AAPT Recommendations for the Undergraduate Physics Laboratory Curriculum Subcommittee Membership, Tech. Rep. (American Association of Physics Teachers (AAPT) Committee on Laboratories, 2014).

[2] . Joint Task Force on Undergraduate Physics Programs, Phys21: Preparing Physics Students for 21st-Century Careers, Tech. Rep. (American Physical Society (APS) and American Association of Physics Teachers (AAPT), College Park, MD, 2016).

[3] B. M. Zwickl, N. Finkelstein, and H. J. Lewandowski, The process of transforming an advanced lab course: Goals, curriculum, and assessments, American Journal of Physics 81, 63 (2013), arXiv:1207.2177.

[4] D. R. Dounas-Frazer, L. Ríos, B. Pollard, J. T. Stanley, and H. J. Lewandowski, Characterizing lab instructors' selfreported learning goals to inform development of an experimental modeling skills assessment, Physical Review Physics Education Research 14, 020118 (2018).

[5] M. Eblen-Zayas, The impact of metacognitive activities on student attitudes towards experimental physics, in 2016 Physics Education Research Conference Proceedings (American Association of Physics Teachers, 2016) pp. 104-107.

[6] T. Feder, College-level project-based learning gains popularity, Physics Today 70, 28 (2017).

[7] J. R. Hoehn and H. J. Lewandowski, Framework of goals for writing in physics lab classes, Physical Review Physics Education Research 16, 010125 (2020).

[8] C. Moskovitz and D. Kellogg, Inquiry-based writing in the laboratory course, Science (New York, N.Y.) 332, 919 (2011).
[9] P. W. Irving and E. C. Sayre, Conditions for building a community of practice in an advanced physics laboratory, Physical Review Special Topics - Physics Education Research 10, 010109 (2014).

[10] V. Howard, Thinking on paper: A philosopher's look at writing, in Varieties of Thinking: Essays from Harvard's Philosophy of Education Research Center, edited by V. Howard (Routledge, New York, 1990) pp. 84-92.

[11] L. O. P. Rivard, A review of writing to learn in science: Implications for practice and research, Journal of Research in Science Teaching 31, 969 (1994).

[12] J. A. Reynolds, C. Thaiss, W. Katkin, and R. J. Thompson, Writing-to-Learn in Undergraduate Science Education: A Community-Based, Conceptually Driven Approach, CBEâLife Sciences Education 11, 17 (2012).

[13] N. Lerner, Laboratory Lessons for Writing and Science, Written Communication 24, 191 (2007).

[14] D. R. Dounas-Frazer, J. T. Stanley, and H. J. Lewandowski, Student ownership of projects in an upper-division optics laboratory course: A multiple case study of successful experiences, Physical Review Physics Education Research 13, 020136 (2017).

[15] H. J. Lewandowski, D. R. Bolton, and B. Pollard, Initial impacts of the transformation of a large introductory lab course focused on developing experimental skills and expert epistemology, in Physics Education Research Conference Proceedings, Vol. 2018 (American Association of Physics Teachers, 2018) arXiv:1807.03385.

[16] We note that these views are likely context dependent and that the data we collected indicate students' views at a particular moment in time. 